\title{
Leitura e escrita na escola: significados e sentidos atribuídos pelas crianças ${ }^{1}$
}

\author{
Débora da Silva Furlaneti ${ }^{2}$ \\ Elvira Cristina Martins Tassoni ${ }^{3}$
}

\section{Resumo}

Este artigo apresenta um recorte de uma pesquisa, que teve como base os estudos de Vigotski. O objeto de estudo foi o processo de alfabetização e as dinâmicas em sala de aula para o entendimento das necessidades e das funções da leitura e da escrita de alunos do 3 o ano do Ensino Fundamental. O objetivo foi investigar quais significações são produzidas pelos alunos para as atividades de leitura e de escrita, propostas pela professora. O material empírico foi produzido por videogravação das observações em sala de aula, acompanhadas por registros em diário de campo; por conversas com as crianças e desenhos produzidos por elas. Os discursos das crianças valorizaram e reconheceram os contextos de usos da leitura e da escrita, aproximando as práticas escolares das práticas sociais cotidianas.

Palavras-chave: Alfabetização; Linguagem Oral e Escrita; Anos Iniciais do Ensino Fundamental; Significados e Sentidos.

\section{Reading and writing at school: meanings and senses attributed by children}

\begin{abstract}
This paper presents a research cutout which was based on Vygotsky's studies. The object of study was the literacy process and the dynamics in the classroom to understand the needs and the reading and writing functions of students in the 3rd grade of Elementary School. The objective was to investigate what meanings are produced by students for the reading and writing activities proposed by the teacher. The empirical material was produced with video recording of classroom observations, accompanied by field diary records, conversations with the children, and the drawings produced by them. The childrens' speeches valued and recognized the contexts of uses of reading and writing, bringing school practice closer to daily social practice.

Keywords: Literacy; Oral and Written Language; Early Grades of Elementary School; Meanings and Senses.
\end{abstract}

\section{Introdução}

A compreensão do processo de alfabetização, mais especificamente da linguagem escrita, tem sido um dos desafios para as práticas dos professores em sala de aula e as relações de ensino estabelecidas na escola. Buscando investigar esse processo, apresentamos o recorte de uma pesquisa empírica, do tipo explicativa, realizada em 2018, com base na Teoria Histórico-Cultural

\footnotetext{
${ }^{1} \mathrm{O}$ presente trabalho é fruto de dissertação.

2 Mestre em Educação pela Pontifícia Universidade Católica de Campinas (PUC-Campinas). Campinas, debora.furlaneti@gmail.com.

${ }^{3}$ Programa de Pós-Graduação em Educação da Pontifícia Universidade Católica de Campinas (PUC-Campinas). Campinas, cristinatassoni@puc-campinas.edu.br.
}

Periódico Horizontes - USF - Itatiba, SP - Brasil - e020054 
de Vigotski, sobre o desenvolvimento do psiquismo humano em uma perspectiva de alfabetização como um processo discursivo, de acordo com Ana Luiza Bustamente Smolka. Discutimos o papel das interações sociais para a aprendizagem, partindo das experiências de 18 alunos de um 3으 ano do Ensino Fundamental e uma professora, para entender as necessidades e as funções da escrita mediante as trocas realizadas em sala de aula e as concepções que eles tinham sobre ler e escrever.

Partimos, então, do discurso apresentado pelas crianças e da relação entre a produção da linguagem dentro da sala de aula, além das experiências com a leitura e com a escrita fora da escola - as funções e os usos como instrumentos de compreensão do mundo. Temos como hipótese que existe uma relação intrínseca entre as atividades de leitura e de escrita desenvolvidas em sala de aula e as significações atribuídas a elas pelos alunos. Ademais, quanto mais distante os usos da escrita escolar estiverem das práticas de escrita sociais que as crianças têm fora da escola, menos possibilidades de compreensão de seu funcionamento terão. Por isso, a pesquisa investigou a dinâmica das relações entre os alunos e as atividades de leitura e de escrita propostas pela professora para identificar articulações entre as práticas de leitura e de escrita escolares com as práticas sociais cotidianas. Assim sendo, pautamo-nos na seguinte questão norteadora: Quais significações são produzidas pelos alunos para as atividades de leitura e de escrita propostas pela professora de uma sala de um 3으 ano do Ensino Fundamental?

Diante dessa necessidade de conhecer e investigar, a produção do material empírico envolveu a videogravação das observações em sala de aula, que contaram com o auxílio de registro em diário de campo; conversas com os alunos em forma de diálogo, também videogravadas; e a produção de desenhos. Buscamos fundamentos teóricos para apresentarmos algumas considerações acerca das interações entre alunos, professora e as atividades de leitura e de escrita realizadas na escola e dos processos de significações. Logo, evidenciamos o papel da mediação para a construção dos conhecimentos sobre a escrita e a leitura durante o processo de escolarização e as práticas pedagógicas de alfabetização, a partir das indagações iniciais da pesquisa, a saber: Como ocorrem as aproximações da leitura e da escrita na escola? Como as interações e os discursos podem favorecer a aprendizagem? É possível estabelecer uma relação entre as práticas sociais de leitura e de escrita cotidianas e as práticas escolares? Por fim, apresentamos as nossas considerações acerca dos resultados obtidos para a continuidade das 
discussões sobre a formação de professores e das reflexões no campo da alfabetização sobre as práticas de letramento.

\section{O processo de alfabetização para a concretização da leitura e da escrita na escola}

O campo da alfabetização possui uma vasta produção acadêmica sobretudo nos anos iniciais do Ensino Fundamental. Optamos em fazer um mapeamento dessa produção científica em forma de artigos no Diretório de Grupos de Pesquisa na Plataforma Lattes no site do Conselho Nacional de Desenvolvimento Científico e Tecnológico (CNPq), que tinham a alfabetização como objeto de investigação. Esse levantamento bibliográfico evidenciou a discussão acerca de várias concepções e estudos sobre a alfabetização no período que selecionamos, entre 2016 e 2018 . O reduzido intervalo temporal deveu-se ao grande volume de artigos encontrados -1.638 entre 2010 e 2018; 960, entre 2014 e 2018; 622, entre 2016 e 2018. Usamos, como critérios de seleção, aplicados ao título e às palavras-chave, as seguintes expressões: alfabetização, linguagem escrita, leitura, letramento e ensino fundamental anos iniciais, resultando em 57 artigos.

A discussão inicial sobre o processo de alfabetização, entendida como ensino da leitura e da escrita, segundo Souza e Amâncio (2016), teve início no século XVIII diante da necessidade de se pensar a formação de professores para a instrução das camadas populares e a preparação de uma mão de obra qualificada com o avanço da industrialização. A educação escolarizada surgiu no século XIX, mas, "[...] no Brasil, de um modo geral, as primeiras escolas de formação de professores passaram por inúmeras adversidades durante sua criação, desenvolvimento e consolidação" (SOUZA; AMÂNCIO, 2016, p.104).

Assim sendo, havia uma grande preocupação na adoção de um método e de um material didático. A disseminação dos métodos sintéticos (de soletração e de silabação) e os analíticos (de palavração) foram abordagens que se apresentaram no material didático propagado nas cartilhas. Dessa forma, a cartilha Caminho Suave foi a mais utilizada no Brasil, permanecendo por sete décadas, "[...] especialmente no período que compreende seu lançamento, em 1948, até 1996, pelo menos, anos em que o PNLD passou a considerar novos critérios para a escolha de livros escolares" (CARDOSO; AMÂNCIO, 2018, p.34).

A concepção de alfabetização para o conhecimento do sistema de escrita alfabética era 
associada ao uso da imagem, das letras e das sílabas do alfabeto. As orientações dadas pelas professoras para o registro da escrita, de acordo com Lacerda (2017), eram marcadas pelo determinismo da fala, incluindo as cópias e os ditados, associadas ao treino e aos gestos motores. Para Frade e Galvão (2016), o ato de escrever para as professoras reportava a falta de recursos, pois somente elas recebiam os livros e, por isso, a lousa foi instituída como suporte; e o giz, como um instrumento para a sistematização da prática pedagógica. Nessa perspectiva, a leitura também era posta como uma decodificação de "caracteres gráficos", sem priorizar a reflexão e os sentidos para "[...] o discurso, produzido no social, [que] leva em conta o possível locutor e interlocutor para quem os materiais são direcionados bem como remete a diferentes perspectivas de ensino, neste caso a leitura e a escrita" (THIES; PERES; MONKS, 2016, p.664).

Smolka (2008, p.16) ressalta que, nesse contexto escolar, “[...] a ideologia da 'democratização do ensino' anuncia o acesso à alfabetização pela escolarização”, e os problemas como a evasão, a repetência e o rendimento dos alunos demonstram a ineficácia dos métodos para os processos de aprendizagem levando ao questionamento dessas práticas pedagógicas. Assim, o conceito de associação, relacionado ao uso de imagens para a aprendizagem, é substituído pelo conceito de interação, considerando o ponto de vista de como o aluno aprende. Além disso, para superar "[...] os problemas da alfabetização e do analfabetismo, encontrou síntese na teoria construtivista resultante das pesquisas de Emília Ferreiro e por ela apresentada como 'revolução conceitual' em alfabetização' (MORTATTI, 2016, p.2268).

A nova concepção de ensino apoiada na epistemologia de Piaget, representada por Ferreiro e Teberosky nos anos de 1980, propõe uma reflexão sobre os processos cognitivos das crianças relacionados à leitura e à escrita por meio da sondagem, tomando por base as hipóteses de escrita construídas pelas crianças. Essa mudança de conceitos torna-se uma referência nacional no ensino brasileiro, possibilitando outra forma de ensinar a ler e a escrever na escola. No entanto, conforme Mortatti (2016), a falta de aprofundamento teórico dos professores levou a incompreensão da teoria que foi entendida como mais um método a ser seguido.

Coelho e Mazzeu (2016) e Pena (2016) corroboram as ideias de Mortatti (2016) e descrevem a incompreensão da teoria construtivista pelo automatismo incluso nos processos, levando "[...] a organização do ensino por meio de uma sequência definida de passos ou etapas a serem vencidas pelos alunos" (COELHO; MAZZEU, 2016, p.2578). E, por consequência, a 
avaliação diagnóstica como um instrumento que considera o processo epistemológico, possibilitando ao professor o papel de "[...] investigador de aspectos culturais e históricos implicados no ato de ler" (PENA, 2016, p.1), é reduzida apenas à identificação do nível de conhecimento das crianças sobre a escrita alfabética (pré-silábica, silábica, silábica-alfabética e alfabética).

Baseando-se nesses contrapontos entre os métodos sintéticos e analíticos e a teoria construtivista com relação ao processo de aquisição da linguagem escrita, Smolka desenvolve, nessa mesma década, entre 1983 e 1985, um estudo sobre a aquisição da linguagem, analisando o contexto da sala de aula e as relações de ensino em uma perspectiva discursiva. Nessa perspectiva discursiva, defendida por Smolka, que assumimos em nosso trabalho, o processo de alfabetização para a concretização da leitura e da escrita na escola depende da interação. A interação como uma forma social de comunicação articulada às hipóteses de escrita apresentadas pelas crianças, a partir da internalização das formas culturais de funcionamento, foi postulada por Vigotski. Esses pressupostos relacionam-se ao conceito de letramento, ultrapassando a dimensão técnica de apropriação dos signos e dos códigos para uma compreensão mais ampla de sentidos diversificados dos diferentes textos e contextos (MACEDO; CHAGAS, 2016).

Nesse processo, marcado pelo contexto social, as palavras ganham significado e sentido, gerando conhecimento. $\mathrm{O}$ trabalho pedagógico na sala de aula leva em conta os aspectos sociais e culturais, as práticas de oralidade, privilegiando os discursos e as concepções trazidas pelas crianças, colocando-as como produtoras de conhecimento.

\section{Implicações das práticas sociais cotidianas às práticas pedagógicas escolares: das interações} discursivas na escola ao processo de significações

Entendemos que, ao adotarmos a Teoria Histórico-Cultural postulada por Vigotski para a compreensão do funcionamento mental que se estrutura por meio das interpretações dadas às participações em práticas socioculturais e às mediações presentes no contexto escolar, é necessário que 
[...] a prática pedagógica e a prática de pesquisa, tanto com crianças como sobre crianças, precisam ser fundamentadas por uma concepção de desenvolvimento infantil que considere a criança como capaz de estabelecer relações com os outros e com o mundo desde o nascimento e que conceba essas experiências vividas socialmente como processos de aprendizagem responsáveis por impulsionar a formação e o desenvolvimento das qualidades na infância (MELLO, 2010, p.5).

Logo, trabalhar com a alfabetização requer muito mais do que apenas o contato das crianças com um ambiente alfabetizador e com a organização desse ambiente. É um processo dialético permeado por um contexto de interações sociais que se constitui nas relações reais entre as pessoas, é mediado pela linguagem, pelos diálogos, pelas atividades e por outros aprendizes.

Para Smolka (2008), com base em Vigotski, trata-se de um trabalho de elaboração individual, uma atividade psicológica mediada dentro da sala de aula, que se instaura no coletivo: nas trocas entre pares, como, por exemplo, professor/aluno, aluno/aluno e aluno/atividade. Essas elaborações, por compreenderem uma atividade psicológica, transcendem a correspondência gráfico-sonora apresentada nas cartilhas e nos livros e dependem da intervenção pedagógica e do reconhecimento da sala de aula como um espaço que assume uma função social.

A intervenção do professor durante esse processo articula os elementos culturais e as trocas discursivas e é "[...] ao mesmo tempo, o principal produto da cultura é o principal instrumento para a transmissão" (SOARES, 2000, p.16) em uma atividade em que "[...] a criança aprende a ouvir, a entender o outro pela leitura; aprende a falar, a dizer o que quer pela escrita" (SMOLKA, 2008, p.63), de forma a verbalizar seus pensamentos, seus sentimentos e suas emoções.

A compreensão da linguagem, nesse contexto da vida social e da necessidade da aprendizagem da leitura e da escrita como uma prática social, e os processos de desenvolvimento são sempre determinados pelo outro articulado ao ambiente, aos eventos sociais e às condições que definem as relações e os papéis a serem desempenhados. Para Rosseti-Ferreira et al. (2004), essa elaboração, marcada pelo papel do outro,

[...] coloca a pessoa em jogos interativos, os quais, em uma rede de relações, impregnada e atravessada pela linguagem, vão abrindo e/ou interditando papéis e lugares possíveis de serem alcançados. Essa característica marca o caráter fundante da dialogia na constituição do ser humano e, 
consequentemente, a sua multiplicidade. A pessoa é múltipla porque são múltiplos e heterogêneos os vários outros com quem interage (ROSSETIFERREIRA et al., 2004, p.28).

Torna-se necessário, portanto, investigar as significações e os sentidos atribuídos pelas crianças nessas relações de ensino para que possamos refletir sobre o que leva as crianças a escrever; o que representa a escrita para elas.

A base para este estudo, pautado em Smolka (2008), pode ser analisada em duas perspectivas: a de quem ensina e a de quem aprende. A de quem ensina, tem como base a natureza social do conhecimento e a mediação, postulada por Vigotski, diferenciando, assim, o modo de pensar a alfabetização para quem aprende. A partir desse entendimento, a concepção de quem aprende só pode ser revelada para quem ensina se forem considerados os aspectos subjetivos, as elaborações e os sentidos. Para Soares (2004, p.6), a diferença fundamental “[...] está no grau de ênfase posta nas relações entre as práticas sociais de leitura e de escrita e a aprendizagem do sistema de escrita".

Considerando que as crianças, ao entrarem na escola, já possuem conhecimentos de inúmeras situações permeadas pela escrita que se diversificam e se ampliam muito fora da escola, a linguagem só assumirá uma dimensão discursiva em sala de aula se forem priorizados os sentidos oriundos desses discursos que articulam os elementos sociais para a compreensão da relação entre as palavras e as coisas. Desse modo,

[...] significa que a linguagem escrita é constituída por um sistema de signos que designam sons e as palavras da linguagem falada, os quais, por sua vez, são signos das relações e entidades reais. Gradualmente, esse elo intermediário (a linguagem falada) desaparece e a linguagem escrita converte-se num sistema de signos que simboliza diretamente as relações reais e as relações entre elas (VIGOTSKI, 1998, p.140).

Dessa maneira, os signos como mediadores semióticos do campo psicológico são meios auxiliares que transformam a atividade interna, desenvolvendo as funções psicológicas superiores. Os signos compartilhados socialmente, quando internalizados, possibilitam a representação mental - os significados e as possibilidades de sentido para aprender promovendo os processos de desenvolvimento. 
A inter-relação desses processos de aprendizagem na escola pode ser identificada por quem ensina, em dois âmbitos - o desenvolvimento real ou atual e o possível, conforme apresentou Vigotski. Prestes (2010), ao discutir os problemas de tradução dos conceitos elaborados pelo autor, esclarece que para se referir aos conhecimentos já internalizados pela criança e que demonstram o seu desenvolvimento efetivo, Vigotski traz o conceito de desenvolvimento real ou atual. Esse conjunto de conhecimentos pode ser observado pelo professor por meio das atividades que a criança consegue realizar sozinha. Indica assim, o que está completo em seu desenvolvimento e representa o que depende de suas ações mentais, de forma independente. Já no que se refere ao desenvolvimento possível, Vigotski define que expressa o que a criança não consegue realizar sozinha, mas pode realizar com a mediação do outro. Realça, desta forma, a capacidade de desenvolver determinadas tarefas e a necessidade da ajuda de alguém mais experiente.

A mediação do professor incide no que Vigotski nomeou de zona de desenvolvimento iminente, tradução indicada por Prestes (2010) que mais se aproxima da expressão russa zona blijaichego razvitia, ao invés de zona de desenvolvimento proximal ou potencial, como se encontra em muitas obras do autor em português. Para Vigotski (apud PRESTES, 2010, p.173), na tradução feita por Prestes, a zona de desenvolvimento iminente

[..] é a distância entre o nível do desenvolvimento atual da criança, que é definido com ajuda de questões que a criança resolve sozinha, e o nível do desenvolvimento possível da criança, que é definido com a ajuda de problemas que a criança resolve sob a orientação dos adultos e em colaboração com companheiros mais inteligentes.

Portanto, a zona de desenvolvimento iminente "(...)define as funções ainda não amadurecidas, mas que encontram-se (sic) em processo de amadurecimento, as funções que amadurecerão amanhã, que estão hoje em estado embrionário" (VIGOTSKI, apud PRESTES, 2010, p.173).

Com base nesses conceitos, o papel do professor é atuar na zona de desenvolvimento iminente, possibilitando avanços que não ocorreriam espontaneamente. Considerando o processo de apropriação do complexo conjunto de sistema de signos, tendo como referência o saber produzido historicamente, as crianças vão estabelecendo relações entre os conhecimentos cotidianos e os científicos. De acordo com Oliveira (1992), os conceitos científicos 
[...] estão organizados em sistemas conscientes de inter-relações. Por sua inclusão num sistema e por envolver uma atitude mediada desde o início de sua construção, os conceitos científicos implicam uma atitude metacognitiva, isto é, de consciência e controle deliberado por parte do indivíduo, que domina seu conteúdo no nível de sua definição e de sua relação com outros conceitos (OLIVEIRA, 1992, p.32).

As conexões entre as práticas escolares de leitura e de escrita e as práticas sociais estão nessa estreita relação entre os conteúdos escolares e a realidade dos alunos, como destacam Almeida e Corrêa (2017), Britto (2017) e Nunes (2017), com os usos concretos da língua, tendo como suporte os gêneros textuais para desenvolver habilidades de leitura e a compreensão do sistema alfabético de escrita. Isso para assegurar o que Amaral, Lima e Nascimento (2016) consideram como a inserção da criança no mundo letrado.

Ao ampliarem esse contexto de leitura, Lovato e Maciel (2016), Goulart (2016) e Almeida e Corrêa (2017) ressaltam que a escola deve prestigiar as atividades compartilhadas por meio do diálogo e da leitura de textos; criar espaços nomeados como cantinho de leitura para a exploração de livros e outros materiais em busca de estabelecer relações/inferências na medida em que se observa e relaciona o que está escrito e o que não está escrito, mas pode ser lido.

Por esse motivo, o conhecimento sobre a leitura e a escrita durante a alfabetização necessita de mediação. Ao aproximar o texto escrito e o contexto lido, os significados e os sentidos, aumentam-se as possibilidades de escrita e essa "[...] aquisição e o domínio da escrita como forma de linguagem acarretam uma crítica mudança em todo o desenvolvimento cultural da criança" (SMOLKA, 2008, p.57). Assim, quanto mais a criança participa, mais chances ela tem de compreender.

\section{Do contexto metodológico à escola investigada}

A pesquisa foi desenvolvida com 18 alunos de uma turma do 30 ano do Ensino Fundamental e uma professora de uma escola municipal de período integral, localizada em uma cidade do interior do estado de São Paulo. A escolha deste ano de escolarização teve como critério o término do ciclo de alfabetização, considerando as experiências já vivenciadas pelas crianças sobre as práticas de alfabetização durante os 10 e 2 anos e parte do 3 ano. A escolha 
da escola deveu-se ao tempo destinado à formação dos professores que, por ser de tempo integral, oferece dois momentos de formação, totalizando quatro horas semanais. As reuniões pedagógicas com a participação de professores e gestão da escola e, ainda um outro momento para reunião com os pares, com o objetivo de socializar as atividades realizadas e refletir sobre o trabalho desenvolvido. Além disso, há o regime de dedicação exclusiva de seus professores.

O objetivo geral da pesquisa foi investigar que significações são produzidas pelos alunos para as atividades de leitura e de escrita, propostas pela professora de uma sala de um 3 을 ano do Ensino Fundamental. Os específicos foram: 1) verificar a dinâmica das relações entre os alunos e as atividades de leitura e de escrita propostas pela professora; e 2) identificar articulações entre as práticas de leitura e de escrita escolares com as práticas sociais cotidianas. Para alcançar esses objetivos, como já apresentado, foram utilizados como instrumentos para produção do material empírico as observações em sala de aula, vídeogravadas e complementadas com anotações em diário de campo, as conversas em forma de diálogo com as crianças, também vídeogravadas e a produção de desenhos.

O período de observações ocorreu durante o mês de setembro de 2018 e contemplou oito horas semanais divididas em dois dias da semana. As observações da pesquisadora das atividades desenvolvidas em sala de aula possibilitaram conhecer o trabalho, realizado pela professora desse 30 ano em conjunto com as outras professoras de outras turmas do mesmo nível de ensino, envolvendo as práticas de leitura e de escrita, tema recorrentemente abordado pela coordenadora durante as reuniões pedagógicas.

A coordenadora pedagógica da escola pesquisada foi professora da rede estadual de ensino por 27 anos e está há sete anos na coordenação dessa escola. A professora da sala participante da pesquisa também já atua por diversos anos na rede e participou de diversas formações oferecidas pelo município. Tanto a coordenadora pedagógica como a professora têm formação no magistério, graduação em Pedagogia e especializações em Psicopedagogia e Educação Inclusiva.

As atividades de escrita, bem como as produções de texto, têm como referência o Projeto Dirigido de Leitura realizado às quintas-feiras. Assim, os alunos dos três terceiros anos eram agrupados "[...] segundo o processo de aquisição de leitura e escrita apresentado por Emília Ferreiro em 1980, ou seja, por níveis de conhecimento: pré-silábico, silábico, silábico- 
alfabético e alfabético", conforme destaca o Projeto Político Pedagógico (PPP) da escola investigada. Apoiadas nessa proposta de alfabetização, as professoras aplicavam uma avaliação diagnóstica e planejavam atividades de acordo com o nível de conhecimento de cada aluno. As aulas aconteciam conjuntamente nesse dia da semana com duas horas/aulas, definidas para todos os grupos de terceiros anos, e cada professora assumia um grupo de alunos organizados em "agrupamentos produtivos", conforme a hipótese de escrita priorizando as trocas para o desenvolvimento de atividades individuais e coletivas. Os alunos eram avaliados constantemente; por isso, quando avançavam no nível de conhecimento ou na hipótese de escrita, eram transferidos para outro grupo e eram propostas outras atividades.

Na sala observada, a aula iniciava com a leitura realizada pela professora de um gênero textual e a proposta de escrita era a transformação daquele gênero em outro - por exemplo, em uma das aulas, a professora utilizou a lousa digital para contar sobre o Dragão de Komodo ${ }^{4}$. Ela contou a história, mostrou um vídeo, e um aluno foi buscar uma revista na biblioteca com imagens e escritas sobre o dragão. Os alunos comentaram o que sabiam, o que eles gostaram e, depois, a professora explicou a atividade: eles se dividiam em grupos de 4 a 5 alunos para a realização da atividade proposta e cada um assumia uma função: um aluno desenhava, o outro ditava o que ia escrever, o outro fazia papel de escriba, e todos corrigiam antes de entregarem para a professora. Nesse dia, a proposta era que, a partir dessa leitura, eles escrevessem uma ficha técnica sobre o Dragão de Komodo. Ao término da atividade, os trabalhos foram expostos pelos corredores da escola, para que os alunos de outros anos pudessem apreciar.

No nosso entendimento, o Projeto Dirigido de Leitura, para além de trabalhar com estratégias variadas a partir do nível de desenvolvimento da escrita, conforme Ferreiro e Teberosky, oportunizava muitas trocas entre as crianças, interações que mobilizavam diversos conhecimentos sobre a linguagem escrita. Da mesma forma criava-se um contexto de necessidade envolvendo leituras e escritas, com propostas de pesquisa, de construção e produção de texto, de reflexões sobre o funcionamento da escrita.

\footnotetext{
${ }^{4} \mathrm{O}$ Dragão de Komodo é o maior lagarto do mundo e também é conhecido como crocodilo da terra. Vive nas ilhas de Komodo, Rinca, Padar e Flores do arquipélago Lasser Sunda, na Indonésia. Disponível em: www. Ninha.bio.org/biologia/komodo. Acesso em: 10 jan. 2020.
} 
As informações obtidas durante as observações em sala de aula serviram de base para as conversas com as crianças em momentos e locais combinados anteriormente com a professora. As conversas em forma de diálogo levaram em conta o que as crianças tinham a dizer além de outras formas de representação, como os gestos e os desenhos, de modo a priorizar a participação e a liberdade de expressão, dispor de um ambiente bem iluminado, arejado, sem barulho ou outro tipo de interferência. O tempo destinado às conversas era reservado após as explicações das atividades e dos períodos que não seriam realizadas as atividades para notas, oferecendo mais uma vez a oportunidade para as crianças se expressarem e não serem prejudicadas quanto ao conteúdo abordado pela professora. O tempo registrado das conversas variou entre 30 e 40 minutos.

Como já mencionado, ao término das conversas, outro recurso utilizado para obter mais informações das crianças participantes foi o desenho, como mais uma via de acesso para a pesquisa com crianças, que poderia auxiliá-las a expressar o que nem sempre conseguem descrever com palavras. Para a realização dos desenhos, a pesquisadora ofereceu às crianças folha de sulfite, lápis de cor, giz de cera, borracha e lápis grafite, e a proposta era que elas desenhassem alguém aprendendo a ler e a escrever, em locais que considerassem que isso fosse possível acontecer.

Desenhar pareceu ser uma atividade muito prazerosa para as crianças; havia o desejo de registrar os detalhes, de colorir e, em algum deles, de escrever para explicitar o que elas achavam que não poderia ficar subtendido. Findados os desenhos, a pesquisadora convidava as crianças para contarem o que elas tinham desenhado. O tempo destinado à produção dos desenhos era maior do que o momento que elas comentavam sobre o que e por que daquele desenho, compreendendo em torno de 25 a 30 minutos.

Além desses instrumentos supracitados, outra técnica utilizada, por ser uma pesquisa de abordagem qualitativa, em busca de validar as informações desse contexto, explorar as evidências e complementar informações obtidas por meio dos outros instrumentos selecionados para o desenvolvimento da pesquisa, foi a análise documental. Os documentos analisados foram: o PPP e os diferentes materiais escolares utilizados em sala de aula, como os cadernos escolares, os livros e as atividades. 


\section{Algumas considerações sobre o que é ler e escrever para as crianças}

Ao analisarmos os dados obtidos com as crianças nas conversas e nos desenhos, considerados narrativas que retratam os diferentes contextos - as situações de aprendizagem que acontecem tanto dentro como fora da escola -, foi possível identificarmos conteúdos que se aproximavam por similaridade. Esses conteúdos inspiraram a construção de categorias de análise e tiveram como referencial teórico a Análise de Conteúdo preconizada por Bardin (2011). Para a autora o conteúdo refere-se à palavra e à imagem (desenho), considerada mais uma forma de representação dentro de um contexto de significações.

Bardin (2011) destaca que o processo de categorização integra duas etapas: a) o inventário - um levantamento e registro dos elementos para abstrair os sentidos; e b) a classificação para separar e ordenar os dados, representando-os de maneira mais simples para o entendimento do leitor.

Após a leitura recorrente das transcrições das conversas, identificamos os conteúdos que se aproximavam por similaridade. Esse processo possibilitou a criação de temas no conjunto dos textos, que inspiraram a construção de categorias de análise: i) Papel da escola; ii) Papel do professor; iii) Papel da família; iv) Práticas de leitura e de escrita na escola; v) Recursos e estratégias que auxiliam a ler e a escrever melhor; e vi) Usos da leitura fora da escola.

Os desenhos foram analisados um de cada vez, e adotamos como procedimento a identificação dos elementos que os compunham, considerando-os uma narrativa que representa as situações de ensino e de aprendizagem dentro da escola e as situações de aprendizagem fora dela.

Nesse contexto, 14 desenhos representaram situações de ensino dentro da escola, reafirmando os assuntos referentes a cinco categorias dentre as seis criadas com base nas conversas: i) Papel da escola; ii) Papel do professor; iii) Papel da família; iv) Práticas de leitura e de escrita na escola; v) Recursos e estratégias que auxiliam a ler e a escrever melhor. Quatro desenhos representaram situações de aprendizagem da leitura e escrita fora da escola, descrevendo aspectos relativos à sexta categoria criada com base nas conversas: vi) Usos da leitura fora da escola.

A seguir, apresentamos cada categoria criada a partir das conversas articuladas com os desenhos, com alguns recortes das concepções e das representações de leitura e de escrita feitas pelas crianças. 


\section{Categoria 1 - papel da escola}

Nesta categoria, a alfabetização foi considerada pelas crianças como uma etapa ou tarefa reservada à escola. A significação atribuída por elas ao papel da escola enfatiza a importância das interações em sala de aula e da mediação por parte do professor para a apropriação de saberes e de elaboração de conceitos. Ao observarmos os seus discursos, constatamos os significados e sentidos atribuídos à escola:

Porque se ela [escola] não existisse, estaríamos burros, não saberíamos nada e não estaríamos aprendendo a ler, a escrever e a falar. Por isso, a escola é o que mais precisa no mundo porque é ela que ensina a ler, a escrever e a falar (Alice ${ }^{5}$ ).

Porque a escola ajuda a gente e também se não fosse pela escola não estaríamos lendo e escrevendo e se a gente não conseguir ler, não dá para ter trabalho, sustentar família... (Joana).

Para representar esse espaço de aprendizagem na escola, na Figura 1, Osmar conta: "Eu desenhei a escola. Eu ia pegar uma folha, no armário, para escrever". Ele disse que ia escrever sobre o que estavam aprendendo.

Figura 1 - Desenho de Osmar

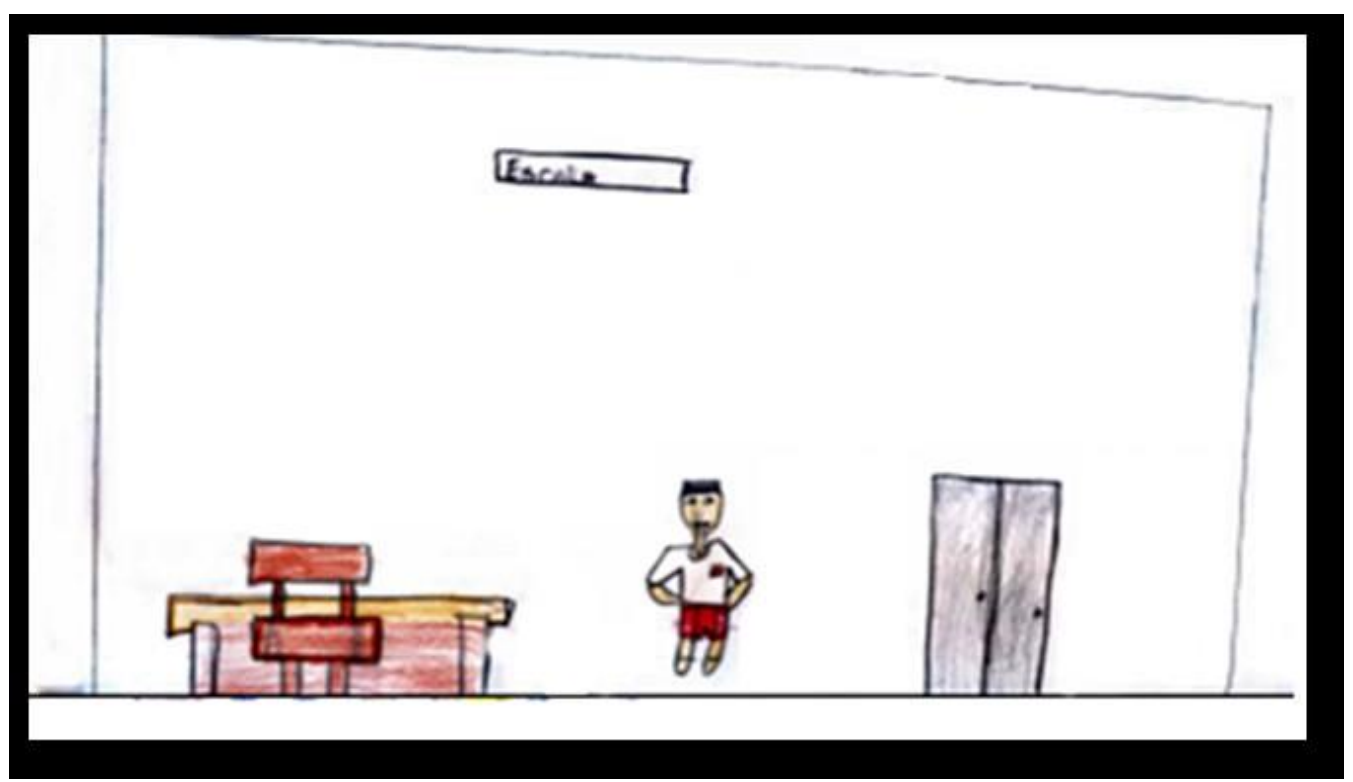

Fonte: Acervo das autoras, 2018.

\footnotetext{
${ }^{5}$ Para preservar a identidade das crianças participantes da pesquisa, os nomes apresentados são fictícios.
}

Periódico Horizontes - USF - Itatiba, SP - Brasil - e020054 
A escola é vista pelas crianças como um lugar de transformação, "[...] rica em conteúdo vivos e relevantes" (COELHO; MAZZEU, 2016, p.2577), que contribuem para a sua formação alterando suas condições na busca de relações entre os saberes e os fazeres, os usos e os contextos, os significados e os sentidos, de modo a assumir as relações entre aprender a ler e a escrever.

Nesse sentido, a escola, para essas crianças, tem a função de auxiliar na apropriação de saberes relacionados à leitura e à escrita como meio de se comunicar, de entender e participar de situações de aprendizagem que fazem parte do presente e do futuro.

\section{Categoria 2 - o papel do professor}

A justificativa para a existência da escola por essas crianças é o resultado do reconhecimento desse local como um lugar que promove desenvolvimento e aprendizagem. Esse processo é fruto das interações e da professora que explica! Mariana exemplifica revelando como é esse processo na escola: "É mais diferente [fora da escola] porque não tem ninguém explicando. Ou por acaso você já viu alguém lá na rua explicando o que é uma placa, sobre os preços? Não. Porque aqui na escola quem explica para a gente é a professora". Alice, por sua vez, declara "eu aprendo a ler treinando com as professoras. A professora lê e usa imagens, às vezes ajuda a entender melhor". E Saulo comenta que "a professora ajuda nos textos, nas atividades" e que, com essa ajuda, "O cérebro fica com mais ideias para a gente pensar e aí a gente vai aprendendo (...).

Ao desenharem a entrega da tarefa para correção, dois alunos destacaram a matemática com as operações de multiplicação e justificaram que desenharam o que estavam aprendendo no momento. No entanto, um desses alunos que desenhou a multiplicação, quando questionado sobre o desenho, fez destaque à mediação da professora na relação com o outro aluno (o Firmino), como se apresenta na Figura 2. 
Figura 2 - Desenho de Ismael

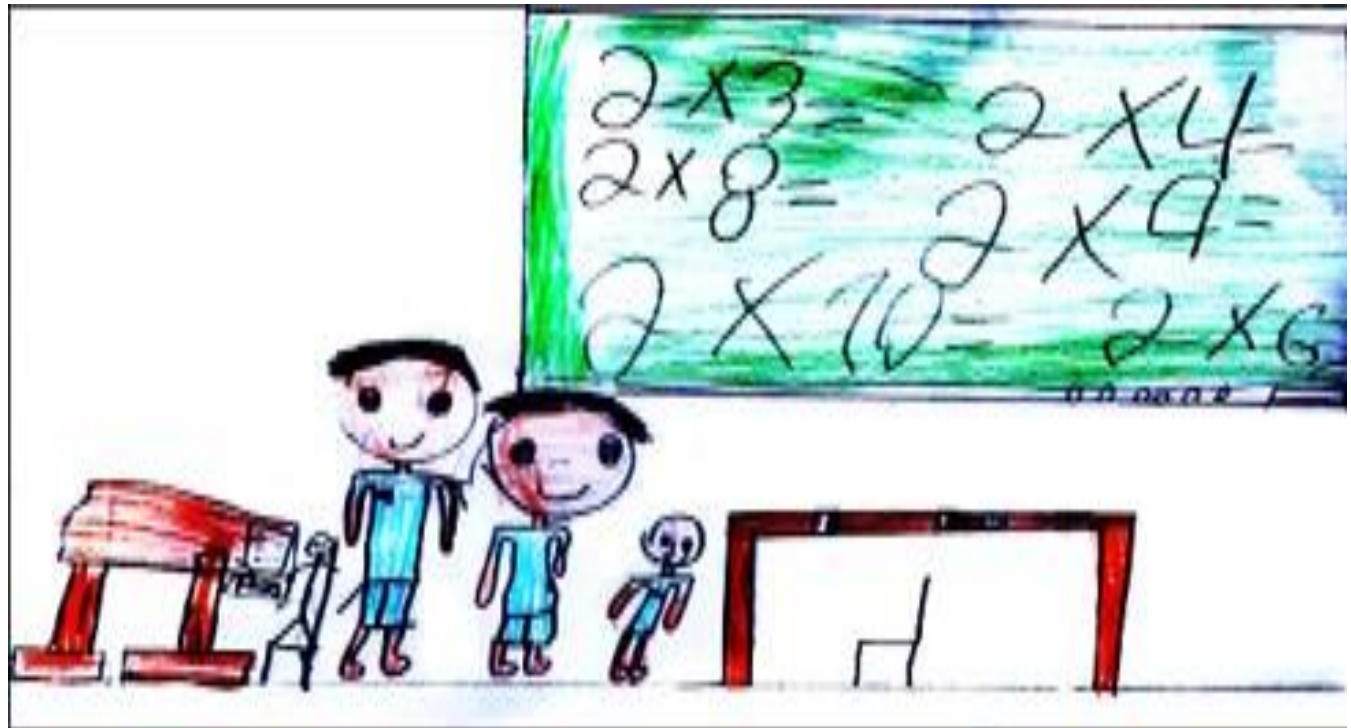

Fonte: Acervo das autoras, 2018.

Ao explicar o que desenhou, Ismael disse: "Eu, outro aluno e o que está próximo da mesa é o Firmino para a professora ajudar com as lições". Firmino era um aluno que veio de outra escola e estava em processo de alfabetização; a professora preparava, entregava e explicava as atividades diferenciadas em alguns momentos para ele na sala de aula e, depois, as corrigia. Com o trabalho realizado em sala de aula e contando com a mediação da professora e de outros colegas (pois era comum as crianças sentarem-se em duplas), foi possível observar o quanto ele se sentia valorizado e confiante para realizar as atividades e aprender: desenvolveu mais o traçado das letras apresentando melhor legibilidade e começava a se arriscar na leitura de palavras. A sua participação nas atividades e o modo como os outros alunos entendiam e corroboravam, demonstravam os princípios da solidariedade e da organização didática e pedagógica da professora em que a "[...] inserção no mundo da escrita é um marco divisor de águas na vida da criança, pois o aprender a ler significa o desvelamento de um mundo novo, cheio de desafios e energias que a instigam a ir além" (LIMA; CARVALHO, 2017, p.36).

Essas representações das falas e dos desenhos produzidos pelos alunos mapeiam as significações para descrever as ações e as práticas adotadas pela professora dentro da sala de aula, demarcando as relações de aprendizagem aproximando os saberes para a apropriação de conceitos. 


\section{Categoria 3 - papel da família}

Embora o papel da família não esteja representado na produção dos desenhos, as crianças comentam, em suas falas, a colaboração dos pais e de outras pessoas da família, do seguinte modo:

Eu aprendo a ler treinando com meus pais e com a minha família. Eu também treinava em casa e a minha vó me ensinava e cada vez que eu errava ela falava: "oh, oh essa é a b, essa é a ba". Na matemática, meu pais me ajudavam, aprendemos usando o dinheiro, a calculadora. (Alice).

Quando meu pai não estava trabalhando, ele faz tipo meu professor, passa conta de matemática, textinhos de português e como a professora doou uns livros para a gente e ele [pai] usa esses livros para brincar de escolinha e quando tem lição de casa ele e minha mãe me ajudam. (Marta).

Para Smolka (2008), ao brincar de escolinha e fazer o papel de professor, o pai representa e significa as atividades. Observamos que esse contexto de interação das famílias, ao compartilharem as experiências com a leitura, com a matemática e com a escrita, levam em conta as elaborações realizadas na escola.

É esse trabalho de imersão e de interação com a leitura e a escrita que, "[...] tanto aquela apresentada pela família, quanto pela escola, tem um caráter formativo e dialógico", (LIMA; CARVALHO, 2017, p.40), possibilitando a apropriação de elementos da cultura presentes no sistema simbólico, organizado em espaços e momentos de interlocução dentro e fora da escola.

\section{Categoria 4 - práticas de leitura e de escrita na escola}

Nesta categoria as crianças comentam sobre o que leem e escrevem na escola, revelando os sentidos dessas práticas. Joana contou como e onde ela realizava a leitura quando entrou na escola:

Sempre aqui na escola todo mundo gostava da minha história, eu lia as imagens e contava a história na secretaria, na biblioteca, para as outras professoras, para as estagiárias e mesmo não sabendo ler todos gostavam porque eu tentava entender aquela história para contar para elas (Joana).

Periódico Horizontes - USF - Itatiba, SP - Brasil - e020054 
Hoje, fizemos docinho de leite em pó, tivemos que ler a receita e aprendemos a cozinhar, foi muito divertido! Antes eu sabia ler na minha imaginação e hoje ler é muito especial e quanto mais eu leio, mais eu aprendo [tanto a ler como escrever], mais aprendo para a vida (Alice).

Escrevo poemas, para ficar inteligente. Eu escrevo bastante e fico bom em escrever e leio livros e fico bom em ler. Porque para escrever é preciso ler livros e ao ler a gente fica esperto, provoca a curiosidade e me faz ler mais e, assim eu vou tendo mais ideias para escrever (José).

Assim, ler possibilita que as crianças aprendam a escrever. O livro, a leitura de texto e a atividade fazem pensar na escrita. O professor, a história e a palavra ajudam a entender como tudo isso funciona.

Ao analisarmos do ponto de vista da Teoria Histórico-Cultural e observarmos essa dinâmica de interações mediadas pela linguagem, pelas atividades, pela professora e por outros aprendizes, é possível perceber os sentidos construídos pelas crianças. As práticas de leitura e de escrita representam suas experiências, seus sentimentos e marcam as relações, transformando suas condições e validando espaços de elaboração e construção social e individual.

Os desenhos ilustram os diferentes momentos em que a leitura acontece: realizada pela professora, por um aluno para a classe toda, a realizada individual e silenciosamente e a que é feita após o término das atividades.

Chamou atenção da pesquisadora a prática de leitura na biblioteca após o almoço! Paulo destacou esse momento relatando que, "quando estou entediado [triste], eu venho à biblioteca na hora do almoço ler e aí eu melhoro, porque a leitura faz a gente entender mais as coisas". Gleice, por sua vez, disse gostar de ler livros e relatou, no desenho 14 (Figura 3), a leitura realizada na biblioteca: "A estante de livros cheios de histórias. Uma menina lendo e uma escrevendo". 
Figura 3 - Desenho de Gleice

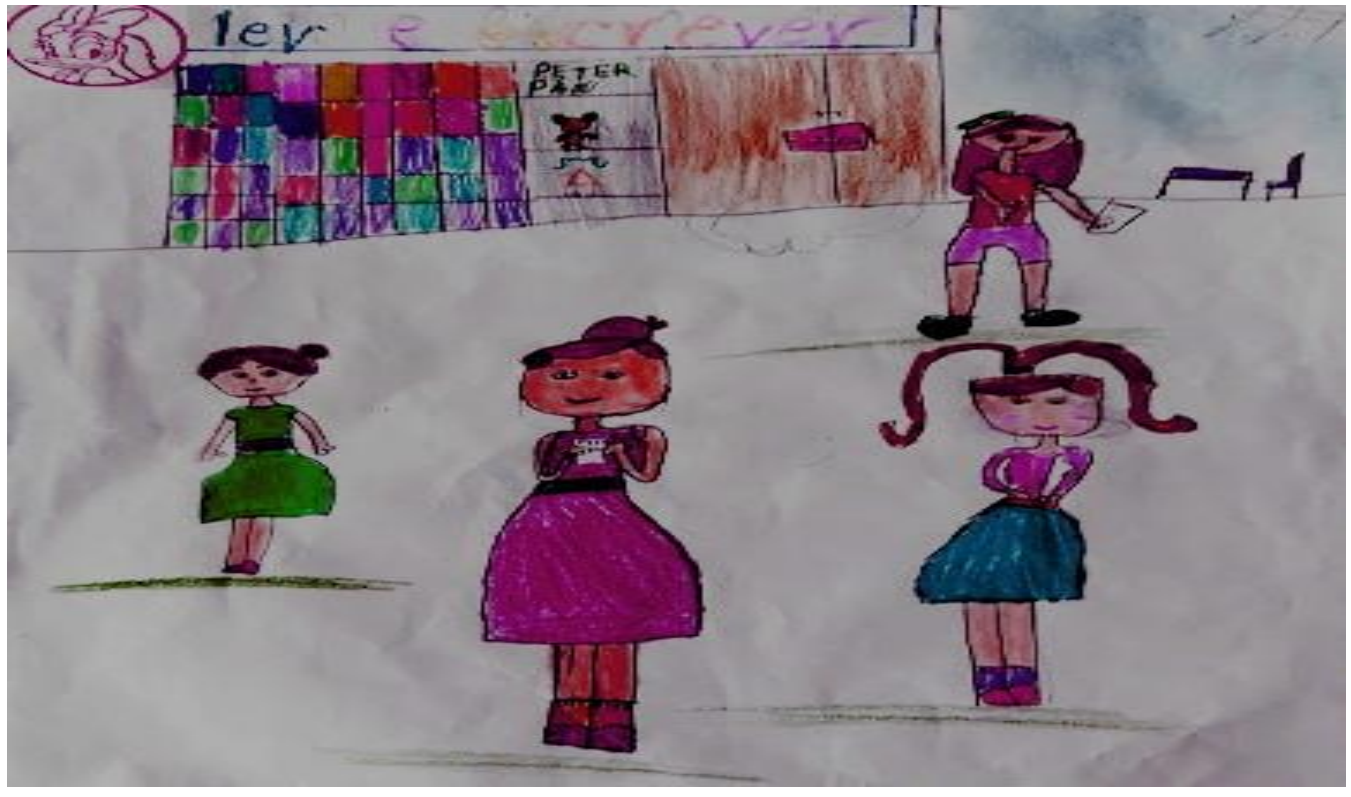

Fonte: Acervo das autoras, 2018.

A influência da leitura na escola também destacada pelas crianças confirma a ideia apresentada por Amaral, Lima e Nascimento (2016, p.17) de que "[...] a escola precisa agir de modo a prestigiar a leitura, não a deixando como uma atividade secundária, pois lendo se aprende a escrever", e esse uso da leitura em sala de aula promove a aprendizagem e as práticas de alfabetização/letramento.

Ao caminhar pelos corredores, também foi possível observar a exposição e os trabalhos realizados em diferentes salas com as crianças. Nesse contexto, Macedo e Chagas (2016, p.11) explicam que "[...] tempo e espaço escolares devem ser pensados como novas oportunidades para a aprendizagem". Essas "oportunidades", também relatadas nas falas das crianças, contribuem para a forma que significam a leitura e a escrita.

Observamos, pois, que as crianças têm experiências com uma significativa diversidade de gêneros textuais, além da leitura deleite realizada de forma contínua pela professora. As estratégias utilizadas antes, durante e após a leitura pela professora, além de outras situações de leitura em voz alta, individual, silenciosa e coletiva, assumem funções diferentes e direcionam a aprendizagem e o envolvimento dos alunos nas atividades. 
Categoria 5 - recursos e estratégias que auxiliam a ler e a escrever melhor

Além da leitura com um propósito, recurso já citado pelas crianças na categoria anterior, a estratégia apontada por algumas para auxiliar a ler e a escrever melhor são o alfabeto, o livro e as imagens:

Eu acho que quem ajuda a aprender a ler no começo é o alfabeto (Joana).

Quando eu leio o livro o que me ajuda a ler quando o livro é difícil, são as imagens. Eu olho nas imagens e daí eu imagino do jeito que eu acho que está escrito. Às vezes a letra é muito pequenininha ou a gente ainda não sabe ler, então a gente olha nas imagens e imagina uma história bem legal. Também tem livros que nem escrita tem, só tem imagens. Dai é para a criança imaginar o que ela acha que está escrito (Mariana).

As crianças destacaram que, quando "a gente" lê a imagem, essa leitura ajuda a pensar nas palavras. Na realidade, a imagem é o suporte principal para a atribuição de sentidos dados à escrita. Da mesma forma, o conhecimento do alfabeto relaciona-se com o reconhecimento que as crianças expressam sobre o conjunto de signos que compõe a escrita. Conhecê-lo é uma condição necessária para avançar na apropriação deste sistema.

Luana complementa a explicação enfatizando o que pode ser feito após a leitura com a professora no desenho 4 (Figura 4): "A menina na sala de aula lendo as palavras na lousa e aprendendo com a professora. Lá no fundo tem a estante de livros para a leitura quando termina a atividade". 


\section{HSE H ORIZON TES}

Figura 4-Desenho de Gleice

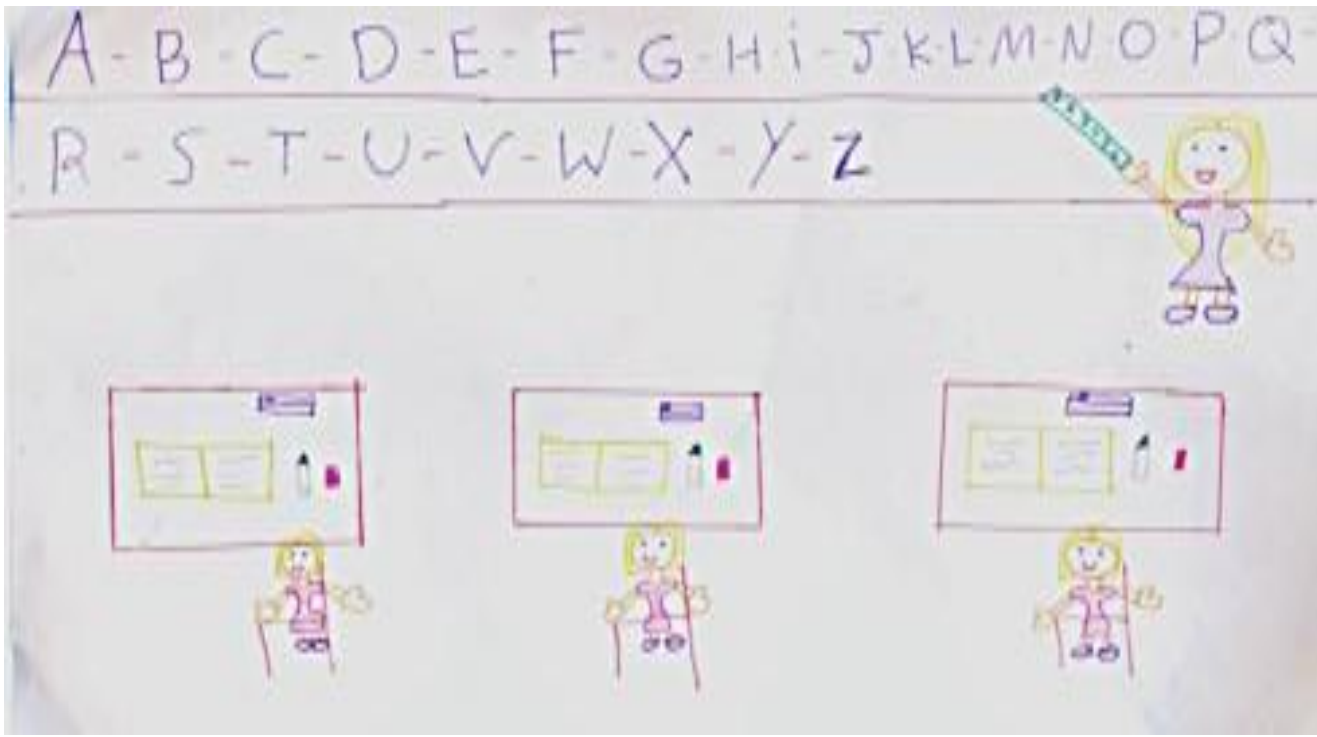

Fonte: Acervo das autoras, 2018.

Diante das descrições sobre os contextos, fica evidente, nos desenhos, os recursos e as estratégias utilizadas pela professora. A leitura em diferentes espaços aproxima as práticas de alfabetização das práticas de letramento, exigindo do leitor a ativação dos conhecimentos prévios, suas percepções e a disponibilidade para a realização dessa tarefa. A leitura compartilhada como um meio de inserir o leitor e o ouvinte no universo da cultura escrita (VELOSO; SANTOS, 2016) é outra estratégia relevante. As imagens destacadas pelas crianças nos livros podem funcionar como recursos oferecidos pelo professor aos alunos, como "[...] meios de interpretação a fim de garantir-lhes diferentes observações acerca do material que está sendo utilizado" (AMARAL; LIMA; NASCIMENTO, 2016, p.18).

Todas essas diferentes situações compõem, de acordo com Guarda e Pereira (2016, p.233), "[...] um processo interativo entre leitor e autor via texto", interdiscursivo que demanda o conhecimento e o uso da língua para a construção de sentidos.

\section{Categoria 6 - usos da leitura fora da escola}

Nos desenhos, as situações de aprendizagem fora da escola são ilustradas por quatro crianças, mas apenas uma faz menção ao local, que é o quintal da casa. Apesar disso, nota-se o 


\section{HSE}

livro como fundo para representar um contexto permeado pela leitura, escrita e interações, como no desenho de Diego, na Figura 5, que explica:

Eu desenhei um lugar que eu criei. É vazio, mas, sempre tem um livro para ler. E quando eu leio os livros começam a flutuar e girar perto de mim. Porque é tipo gravidade zero, então sempre que você fala de um livro, outros livros são atraídos e vão girando no ar para eu escolher o que eu quero ler. E sempre que acabo de ler um livro eu devolvo e escolho outro.

Figura 5 - Desenho de Diego

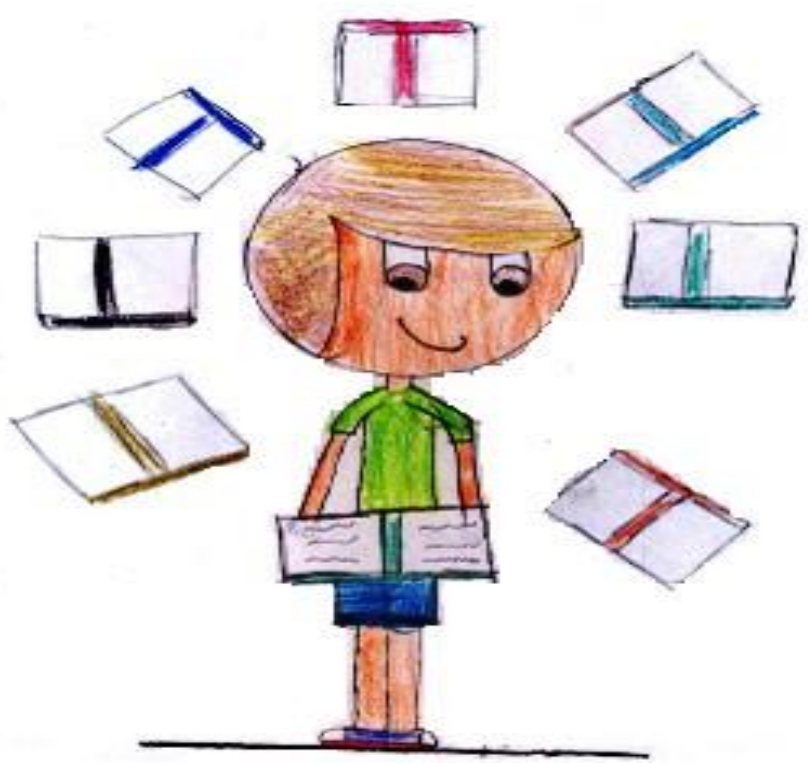

Fonte: Acervo das autoras, 2018.

Em outros comentários, as crianças relatam situações de seu cotidiano, como nos exemplos a seguir:

Eu leio na minha casa, na rua, na calçada as palavras que eu não conheço (Mateus).

No supermercado, eu leio os números, dá pra gente ler em reais (Isla).

Na sorveteria, minha mãe me dá o cardápio para a gente escolher e aí eu preciso saber ler (Luana).

Periódico Horizontes - USF - Itatiba, SP - Brasil - e020054 
Ler e escrever, embora em dimensões e lugares diferentes, são apontados como atividades que assumem uma função social. "Quando a gente vai numa loja e tem a placa de promoção a gente vê o preço e aí a gente também vai aprendendo", diz Mariana.

A leitura de placas, anúncios e cardápios envolve o que Soares $(1998$, p.72) considerou “[...] um conjunto de práticas sociais ligadas à leitura e à escrita em que os indivíduos se envolvem em seu contexto social". A vivência de práticas que possibilitam esses usos da língua seguramente auxiliará na compreensão do porquê e para que se utilizam a leitura e a escrita relacionando as práticas escolares e as práticas sociais cotidianas.

Diante do material empírico apresentado, alguns aspectos nos chamaram atenção e podem ter contribuído para a forma como as crianças significaram as práticas de leitura e de escrita na escola.

A diversidade de recursos com o auxílio da tecnologia dinamizava a interação entre professora e alunos, enriquecia o trabalho com o uso de diferentes imagens, textos e sons e oferecia a possibilidade de os alunos dialogarem com diferentes linguagens, tanto a verbal, como a escrita e a visual, explorando diferentes pontos de vista e a produção de sentidos. Os recursos de multimídia, como vídeos, imagens e a navegação na internet, tendiam a aproximar as crianças dos significados compartilhados socialmente, pela disponibilidade de acesso a dicionários e links que facilitavam a pesquisa em diferentes suportes de escrita.

Havia oportunidades frequentes de os alunos trabalharem em pequenos grupos, onde socializavam suas aprendizagens e registravam o que haviam aprendido. lam regularmente à biblioteca para o empréstimo de livros, realizavam apresentações de leitura para outros alunos, faziam exposições de seus trabalhos escritos nos corredores da escola, podendo observar os trabalhos de outros.

A mediação da professora durante as atividades, as interações entre os alunos e a ampliação da ideia de leitura envolvendo outras linguagens, as práticas de leitura desenvolvidas em sala de aula, bem como os motivos apresentados para se escrever, constituíram-se em elementos importantes para os sentidos atribuídos pelos alunos às práticas de leitura e de escrita que realizavam na escola. 


\section{Considerações finais}

A investigação das significações atribuídas pelos alunos para as atividades de leitura e de escrita propostas pela professora de um 30 ano do Ensino Fundamental evidenciou a importância de um ensino que oportunize as interações em sala de aula entre alunos-professora, alunosalunos e alunos-professora-leitura-escrita. A mediação e a intervenção da professora durante as atividades foram apontadas pelas crianças como um aspecto importante para a aproximação e o entendimento das práticas sociais cotidianas, de modo a promover a aprendizagem e o desenvolvimento.

As atividades de leitura e de escrita em sala de aula estavam muito inter-relacionadas. Envolviam a leitura diária pela professora, a pesquisa para a realização das atividades pelos alunos e a realização de desenhos. Além disso, os alunos liam ao término das atividades; na frente da sala, para os demais alunos; na biblioteca; durante o almoço; e em outras salas de aula durante apresentações que faziam de seus trabalhos. Com base na Teoria Histórico-Cultural, destacamos que a atividade das crianças com/nas práticas de leitura e de escrita vivenciadas na escola possibilitou a construção de sentidos sociais para os usos da escrita. O que elas realizavam em sala de aula e a forma como realizavam, acreditamos ter produzido (trans) formações no processo de constituição dessas crianças como cidadãos.

Assim sendo, podemos afirmar que esta pesquisa apresentou um quadro favorável para a reflexão sobre as práticas de leitura e de escrita durante o processo de alfabetização. Pensar sobre quais práticas pedagógicas podem contribuir para uma formação leitora e escritora competente, aliada ao domínio da língua materna, no que se refere à normatividade e à discursividade, ainda é um dos desafios para a escola contemporânea. Dessa forma, ressaltamos, além disso, a necessidade de manutenção de investimentos na formação, inicial e em serviço, de professores.

\section{Referências}

ALMEIDA, A. C.; CORRÊA, H. T. Memórias na sala de aula: análise de uma prática pedagógica na perspectiva do letramento literário. Linhas, Florianópolis, v.18, p.108-130, 2017. DOI: http://dx.doi.org/10.5965/1984723818372017108. 
AMARAL, S. F.; LIMA, M. C.; NASCIMENTO, A. L. R. Práticas de leitura no 10 ciclo do ensino fundamental: um estudo de caso. Linha Mestra, Campinas, n.30, p.11-15, set./dez. 2016.

BARDIN, L. Análise de conteúdo. São Paulo: Edições 70, 2011.

BRITTO, L. P. L. O engodo subjetivista e a formação do leitor. Nuances: Estudos sobre Educação, São Paulo, v.28, p.8-23, 2017. DOI: https://doi.org/10.14572/nuances.v28i2.5093.

CARDOSO, C. J.; AMÂNCIO, L. N. B. Cartilha Caminho Suave: aspectos da constituição, trajetória e permanência na alfabetização brasileira. Revista Brasileira de Alfabetização, Vitória, v.1, n.7, p.33-60, jan./jun.2018.

COELHO, I. T.; MAZZEU, F. J. C. Notas introdutórias para um método histórico-crítico de alfabetização. Revista Ibero-Americana de Estudos em Educação, Araraquara, v.11, p.25762593, 2016.

FRADE, I. C. A. S.; GALVÃO, A. M. O. Instrumentos e suportes de escrita no processo de escolarização: entre os usos prescritos e os não convencionais (Minas Gerais, primeira metade do século XX). Revista Brasileira de História da Educação, Maringá, v.16, n.1, p.297-334, jan./abr. 2016. DOI: http://dx.doi.org/10.4025/rbhe.v16i1.775.3.

GOULART, I. C. V. A representação da leitura entre versos e palavras. Linha Mestra, Campinas, v.10, p.470-475, 2016.

GUARDA, M. L. S.; PEREIRA, M. R. A. Ensino de leitura: uma proposta para o desenvolvimento da habilidade de inferir. Letras \& Letras, Uberlândia, v.32, n.2, p.231-257, jul./dez. 2016. DOI: https://doi.org/10.14393/LL63-v32n2a2016-12.

LACERDA, M. P. Cachimônia: pela alfabetização lenta. Linhas, Florianópolis, v.18, p.347-376, 2017. DOI: http://dx.doi.org/10.5965/1984723818362017347

LIMA, F. R.; CARVALHO, M. A. F. Olhares subjetivos para a alfabetização. Pensares em Revista, São Gonçalo, v.1, p.31-46, 2017. DOI: https://doi.org/10.12957/pr.2017.33434

LOVATO, R. G.; MACIEL, F. I. P. Leitura deleite como espaço de incentivo à leitura e construção do conhecimento. Revista Brasileira de Alfabetização, Vitória, v.1, n.7, p.74-89, 2016.

MACEDO, M. S. A. N.; CHAGAS, V. I. Alfabetização no contexto da escola integrada: uma perspectiva etnográfica. Revista Brasileira de Alfabetização, Vitória, v.1, n.7, p.209-226, 2016.

MELLO, S. A. O lugar da criança na pesquisa sobre a infância: alguns posicionamentos na perspectiva histórico-cultural. Revista Reflexão e Ação, Santa Cruz do Sul, v.18, n.2, p.183-197, jul./dez. 2010.

MORTATTI, M. R. L. Os órfãos do construtivismo. Revista Ibero-Americana de Estudos em 
Educação, Araraquara, v.11, n.esp.4, p.2267-2286, 2016. DOI:

https://dx.doi.org/10.21723/riaee.v11.esp4.9193

NUNES, M. F. Literatura infantil: mediar práticas de leitura envolvendo a cultura escrita a letrada. Textura, Canoas, v.19, p.73-92, 2017.

OLIVEIRA, M. K. Vygotsky e o processo de formação de conceitos. In: LA TAILLE, Y.; DANTAS, H. (orgs.). Piaget, Vygotsky e Wallon: teorias psicogenéticas e discussão. São Paulo: Summus, 1992. p.23-34.

OLIVEIRA, M. K. Vygotsky: aprendizado e desenvolvimento: um processo sócio-histórico. 5.ed. São Paulo: Scipione, 2010. [Coleção Pensamento e ação na sala de aula].

PENA, S. C. Avaliação diagnóstica da alfabetização: a experiência dos alunos de pedagogia/ PARFOR da UFPA. In: FÓRUM INTERNACIONAL DE PEDAGOGIA - FIPED, 8, 2016, Imperatriz. Anais eletrônicos [...]. Imperatriz: Universidade Federal do Maranhão, 2016. Disponível em: https://editorarealize.com.br/revistas/fiped/trabalhos/TRABALHO_EV057_MD1_SA36_ID938_ 06092016084138.pdf. Acesso em: 10 jan.2010.

PRESTES, Z. R. Quando quase não é quase a mesma coisa: análise de traduções de Lev Semionovitch Vigotski no Brasil - repercussões no campo educacional. 2010. 295f. Tese (Doutorado em Educação) - Programa de Pós-Graduação em Educação da Faculdade de Educação, Universidade de Brasília, Brasília, 2010.

ROSSETI-FERREIRA, M. C. et al. Rede de significações e o estudo do desenvolvimento humano. In: BARBOSA, M. C. S. (org.). Compromisso com a complexidade. Porto Alegre: Artmed, 2004. p.131-134.

SMOLKA, A. L. B. A criança na fase inicial da escrita: a alfabetização como processo discursivo. 12.ed. São Paulo/ Campinas: Cortez /Editora da Universidade Estadual de Campinas, 2008. [Coleção Passando a limpo].

SOARES, M. Concepções de linguagem e o ensino da Língua Portuguesa. In: BASTOS, N.B. (org.). Língua Portuguesa: história, perspectiva, ensino. São Paulo: EDUC, 1998. p.53-60.

SOARES, M. Linguagem e escola: uma perspectiva social. 17.ed., 2.impr. São Paulo: Ática, 2000. [Série Fundamentos].

SOARES, M. Letramento e alfabetização: as muitas facetas. Revista Brasileira de Educação, Rio de Janeiro, n.25, p.5-17, jan./ abr. 2004.

SOUZA, T. F. M.; AMÂNCIO, L. N. B. História da alfabetização, um percurso possível: pesquisa, fontes e sujeitos da memória. Revista Brasileira de Alfabetização, Vitória, v.1, n.3, p.93-118, jan./jul. 2016. 
THIES, V. G.; PERES, E. T.; MONKS, J. C. Títulos de livros para o ensino da leitura e da escrita como projeto enunciativo (1950-2006). Educação, Santa Maria, v.41, p.657-670, 2016.

VELOSO, G. M.; SANTOS, F. A. Leitura compartilhada de textos literários na alfabetização de crianças de 6 anos. Revista Brasileira de Alfabetização, Vitória, v.1, n.4, p.69-88, jul. /dez. 2016.

VIGOTSKI, L. S. A formação social da mente: o desenvolvimento dos processos psicológicos superiores. Trad. José Cipiolla Neto e Solange C. Afeche. 6.ed. São Paulo: Martins Fontes, 1998.

Recebido em março 2020

Aprovado em setembro 2020. 